\title{
La subsistencia en el Pleistoceno Superior en la Península Ibérica: problemas tafonómicos y zooarqueológicos
}

\author{
José Yravedra Sáinz de los Terreros *
}

\section{RESUMEN}

Este artículo plantea una revisión bibliográfica de los estudios zooarqueológicos realizados en diferentes yacimientos del Pleistoceno

Superior de la Península Ibérica. En este análisis se ha visto como las limitaciones implícitas en los métodos de investigación de aquellos yacimientos excavados en fechas antiguas y la escasez de análisis tafonómicos adecuados sugiere la necesidad de realizar nuevas investigaciones más meticulosas en el futuro, así como una revisión tafonómica de aquellos lugares ya excavados. A pesar de los numerosos problemas observados, se pueden hacer ciertas precisiones que deberán ser confirmadas en futuros trabajos. De esta forma puede observarse como las estrategias de subsistencia de todo este momento indican una continuidad taxonómica progresiva que culmina en la especialización final del

\section{ABSTRACT}

The Upper Pleistocene zooarchaeology at the Iberian Peninsula is discussed in this paper. Some problems such as the heterogeneous methodological approach of each site indicate a pessimistic vision of our zooarchaeology. In spite of this problem, we can make some interpretations that should be confirmed in futures works. This work concludes that taxonomically there is continuity in the subsistence strategies until the Magdalenian specialization. It is also treated the debate of the subsistence in the transition between Neandertals and Modern Humans. This one supports the hypothesis of no subsistence diferences between both hominids

\footnotetext{
* Becario FPU. Departamento de Prehistoria e Historia Antigua. UNED. Senda del Rey, 7, 28040 Madrid. jyravedra@teleine.es
} 
Magdaleniense. Es importante también a la luz de los escasos análisis tafonómicos realizados las similitudes subsistenciales de neandertales $y$ primeros humanos modernos.

PALABRAS CLAVE Zooarqueología, Patrones de Representación Anatómica, Marcas de corte, Musteriense, Paleolítico Superior, Solutrense, Magdaleniense.
KEY WORDS

Zooarchaeology, Skeletal

Representation, Cut Marks, Musterian, Upper Palaeoirithic, Solutrean, Magdalenian.

\section{INTRODUCCIÓN}

En este trabajo se realiza una revisión bibliográfica de todos los yacimientos del Pleistoceno Superior de la Península Ibérica que cuentan con estudios zooarqueológicos. La intención inicial era la determinación de posibles diferencias subsistenciales entre neandertales y primeros humanos modernos. Pero por diversas circunstancias se ha ampliado el marco cronológico seleccionado a todo el Paleolítico Superior con el fin de evaluar qué tendencias económicas se produjeron durante toda la secuencia y observar con mayor perspectiva las posibles divergencias entre el Paleolítico Medio y el Superior. Esto ha llevado a analizar un amplio conjunto de yacimientos y niveles que parecen mostrar algunos problemas que se irán exponiendo en el transcurso de este trabajo.

A pesar de ello los diferentes análisis arqueozoológicos permiten hacer una serie de inferencias que deberán confirmarse, contrastarse y discutirse en futuros trabajos. En ellos se deberá primar una metodología más apropiada, con interpretaciones basadas principalmente en análisis tafonómicos en contraposición a los patrones de representación esquelética, que han resultado ser bastantes ambiguos (Marean 1998; Marean y Kim 1998; Marean y Assefa 1999; Domínguez Rodrigo 1999; Yravedra 2000, 2001; Yravedra et alli. 2002).

\section{METODOLOGÍA: PROBLEMAS Y PERSPECTIVAS}

Los métodos arqueozoológicos que más suelen utilizarse son el número de restos identificables (NISP), el número mínimo de individuos $(M N I)$, el número mínimo de elementos (MNE), el mínimo número de unidades anatómicas animales (MAU), los índices de utilidad alimenticia (MGUI) y el 
peso $(W$. La finalidad de estos métodos es identificar que especies aparecen, en que proporción y que causas pueden haber influido en su representación. También se pretende identificar diferentes aspectos como el origen de los restos, que agente es el responsable de la acumulación ósea y, en caso de ser antrópico que patrón se ha seguido, especialización o diversificación en función del NISP o el MNI. Sobre el tema de la especialización han opinado bastantes autores. Altuna (1994), la interpreta cuando una taxón supera el $70 \%$ de los restos, frente a otros como Díez (1992) o Martínez Moreno (1997), que son más partidarios de observarla a partir del $85 \%$ de los restos. Con otros métodos como los análisis de edades, se puede establecer qué patrones de mortandad hay (atricional o catastrófico), en qué momento se ha producido, e incluso sí el acceso a los recursos cárnicos ha sido primario o secundario (Stiner 1994). Mediante este patrón se han definido episodios de caza especializada sobre manadas de crías y hembras (Soto 1984; Altuna 1986, 1994; Altuna et alli. 1985; Barandiarán y Cava 1989; Straus 1992), de caza de manadas en invierno y otra individual en las estaciones de cría (Quesada 1997 a). Finalmente con el MGUly el $W$ se busca establecer qué taxón contribuyó a ser el principal aporte alimenticio.

Antes de mostrar los problemas de estos métodos hay que resaltar que algunos de ellos como el MGUl y el MNE casi no se han utilizado en nuestro país, salvo las excepciones de los trabajos de Díez (1992), Martínez Moreno $(1993,1998)$ y Díez et alli. (1999). En el caso de otros como el NISP y el MNI no se profundizará en la ambigüedad de las interpretaciones tafonómicas y zooarqueológicas que supone la utilización de uno u otro, tal y como han hecho otros autores (Morales 1990; Martínez Moreno 1993, 1995; Blasco 1996). En cualquier caso todos estos métodos tienen problemas propios, al tiempo que muestran una serie de aportaciones que pueden ayudar a interpretar la fauna de un yacimiento (tabla 1).

Aún así, son discutibles algunas de las inferencias que se hacen en función de unos u otros parámetros. No es lo mismo hablar de una especialización basada en el NISP que en el MNI, ya que según se trate de una u otra se sobrerepresentarán determinadas especies. De esta manera ante un conjunto con pocos restos de un taxón, su $M N I$ tendrá una proporción mayor que la mostrada por el NISP, como ya han indicado algunos autores (Morales 1990; Martínez Moreno 1993, 1995; Blasco 1996). De esta forma en un conjunto en el que determinado taxón sufra un patrón de aprovechamiento muy exhaustivo y, por tanto, una gran fragmentación, tenderá a sobrerrepresentar su NISP. Por eso es necesario calcular el MNE, ya que es el único método capaz de dar cuenta de la fracturación del conjunto y de una representación anatómica más aproximada a la original. 


\section{Tabla 1. Problemática y aportaciones de los distintos métodos zooarqueológicos}

\begin{tabular}{|c|c|c|}
\hline MÉTODOS & PROBLEMÁTICA & APORTACIÓN \\
\hline $\begin{array}{l}\text { NISP } \\
\text { (n. }{ }^{\circ} \text { de restos) }\end{array}$ & $\begin{array}{l}\text { Tiende a sobrerrepresentar las es- } \\
\text { pecies más fracturadas }\end{array}$ & $\begin{array}{l}\text { - Grado de fragmentación. } \\
\text { - Abundancia de especies. } \\
\text { - Intensidad de la ocupación. }\end{array}$ \\
\hline $\begin{array}{l}M N E \text { ( } \mathrm{n}^{\circ} \\
\text { de elementos) }\end{array}$ & $\begin{array}{l}\text { Problemas en la reconstrucción de } \\
\text { determinadas secciones. }\end{array}$ & $\begin{array}{l}\text { - Es el que más se aproxima a la } \\
\text { representación anatómica real. } \\
\text { - Abundancia de especies. } \\
\text { - Grado de fragmentación. }\end{array}$ \\
\hline $\begin{array}{l}M N I\left(\mathrm{n}^{\circ}\right. \\
\text { de individuos) }\end{array}$ & $\begin{array}{l}\text { Acrecienta la presencia de los indi- } \\
\text { viduos con menos restos. }\end{array}$ & $\begin{array}{l}\text { - Es el que más se aproxima a } \\
\text { la representatividad real de } \\
\text { especies. }\end{array}$ \\
\hline Edades & $\begin{array}{l}\text { Gran variabilidad tanto dentro de los } \\
\text { grupos humanos como entre los car- } \\
\text { nívoros. } \\
\text { - No se puede establecer qué agente } \\
\text { es el responsable de una acumula- } \\
\text { ción. }\end{array}$ & $\begin{array}{l}\text { - Preferencias o aleatoriedad en } \\
\text { el acceso de los distintos indi- } \\
\text { viduos. } \\
\text { - Muerte catastrófica o atriciona- } \\
\text { lidad en caso del estudio de las } \\
\text { periquimatas de los dientes. } \\
\text { - Estacionalidad. }\end{array}$ \\
\hline $\begin{array}{l}\text { MGUI } \\
\text { (Utilidad } \\
\text { alimenticia) }\end{array}$ & $\begin{array}{l}\text { - Gran variabilidad interna dentro de } \\
\text { las propias especies, tanto en fun- } \\
\text { ción del tamaño, como del sexo, la } \\
\text { edad, etc. }\end{array}$ & - Principal aporte cárnico. \\
\hline $\begin{array}{l}\text { W (Peso de lo } \\
\text { consumido) }\end{array}$ & $\begin{array}{l}\text { - Variabilidad de las propias especies. } \\
\text { - Transporte diferencial. }\end{array}$ & - Principal aporte cárnico. \\
\hline $\begin{array}{l}\text { Representación } \\
\text { Anatómica }\end{array}$ & $\begin{array}{l}\text { - Conservación diferencial. } \\
\text { - Transporte diferencial. } \\
\text { - Desarticulación diferencial. } \\
\text { - Procesos de Investigación. } \\
\text { - Alteraciones de Carnívoros. }\end{array}$ & $\begin{array}{l}\text { (En combinación con los estu- } \\
\quad \text { dios de marcas) } \\
\text { - Acceso a altas porciones cár- } \\
\text { nicas. } \\
\text { - Conservación Diferencial. }\end{array}$ \\
\hline $\begin{array}{l}\text { Patrones de } \\
\text { alteración ósea }\end{array}$ & $\begin{array}{l}\text { Mala conservación de las corticales. } \\
\text { - Procesos Geológicos y Biológicos } \\
\text { que pueden alterar las corticales. }\end{array}$ & $\begin{array}{l}\text { - Agentes de la acumulación. } \\
\text { - Grado de alteración y consumo. } \\
\text { - Caza o carroñero. } \\
\text { - Acción de otros agentes. } \\
\text { - Historia Tafonómica. }\end{array}$ \\
\hline $\begin{array}{l}\text { Etnoarqueología } \\
\text { y trabajos con } \\
\text { carnívoros }\end{array}$ & $\begin{array}{l}\text { - Riesgo de la analogía y problemáti- } \\
\text { ca de los datos basados en este tipo } \\
\text { de información. } \\
\text { - Variabilidad analógica. }\end{array}$ & $\begin{array}{l}\text { - Marco referencial comparativo. } \\
\text { - Modelos analógicos. }\end{array}$ \\
\hline
\end{tabular}


En otros trabajos recientes se ha mostrado cómo las interpretaciones basadas en las edades de los individuos son discutibles. Así, frente a autores que piensan en un acceso cárnico secundario según la edad de los individuos (Stiner 1994), existen otros muchos que muestran cómo es insostenible mantener tal opinión según este criterio, ya que se ha observado una gran variabilidad demográfica entre las presas de carnívoros y cazadores-recolectores actuales (Domínguez Rodrigo 1996). De igual forma, aquellas interpretaciones que hacen alusión a la estacionalidad, a la caza de manadas de crías y hembras o a los episodios de caza por conducción de una manada hasta un lugar de muerte, son bastante problemáticas si no cuentan con un buen análisis de coronas dentarias y periquimatas, que confirmen la mortandad en un mismo momento. Los estudios de Lieberman, han permitido desarrollar ciertos criterios de estacionalidad que pueden ayudarnos a diferenciar si dos individuos o más son contemporáneos de un mismo episodio de muerte y, por tanto, de un mismo evento cinegético (Lieberman 1993).

En lo que se refiere a otros métodos como el MGUl y el $W$, las interpretaciones que se hacen con ellos también presentan problemas. La gran variabilidad interna de cada taxón y otros condicionantes como la edad, el sexo o el estado nutricional, pueden influir en las diferencias entre una misma o distinta especie, como ha quedado de manifiesto en los estudios de Blumenschine y Caro (1986) y Domínguez Rodrigo (1999). Por otro lado está variabilidad no sólo afecta a la carne, sino también al contenido medular, como demostró el análisis de Blumenschine y Madrigal (1993) sobre 27 ungulados esteafricanos diferentes. Igualmente también hay que considerar el transporte diferencial practicado por diversas sociedades como los Nunamiut (Binford 1978, 1981), los Hadza (O'Conell et alli. 1990, 1991, 1992; Lupo 2001), los Bisa (Crader 1983), los Sam (Bartram 1993), los Kua (Bartram 1995), etc.

Por último destacar las hipótesis que intentan definir un acceso primario (caza) o secundario (carroñeo) en furición de los elementos anatómicos representados en el yacimiento (Binford 1984; Binford y Stone 1986; Klein y Cruz Uribe 1994; Stiner 1994). Así ante una representación esquelética rica en elementos cárnicos, como son las secciones apendiculares proximales y las axiales, son interpretados como un acceso primario y, por tanto, relacionados con un posible episodio cinegético. Por el contrario un predominio de segmentos craneales y apendiculares distales, son más indicativos de un acceso secundario relacionado con ciertas estrategias oportunistas.

En principio, estas interpretaciones tienen cierta lógica, pero diferentes aspectos han mostrado que las conclusiones basadas en estos patro- 
nes son bastante problemáticas, ya que demasiados factores pueden condicionar la representación esquelética final (tabla 1).

En primer lugar, destacar el transporte diferencial practicado por las diferentes sociedades, entre las que se puede destacar aquellas a las que anteriormente se hizo referencia y que invalidan cierto tipo de interpretaciones como las de González Echegaray (1980) o Bernaldo de Quirós (1980) para el Paleolítico Superior cantábrico. En segundo lugar están los distintos patrones de desarticulación, entre las que autores como Hill (1975) ha documentado 25 procesos diferentes de desarticulación.

En tercer lugar destaca la conservación ósea diferencial, que cambia según la edad de los individuos (Binford y Bertram 1977), el tamaño de las presas (Bartram 1993; Marean 1998), los procesos posdeposicionales que intervienen en la sedimentación y las propias características del hueso, como la forma, la densidad, etc. (Lyman, 1994). De forma que tienden a sobrerrepresentarse aquellos elementos más resistentes como los dientes y los metapodios condicionando de forma significativa la muestra esquelética final. Aunque junto a estos factores hay otros dos agentes que tienen una influencia mayor en la configuración del registro óseo final.

Por un lado la acción de los procesos de investigación han tendido a sobrerrepresentar aquellos elementos más fácilmente reconocibles, que casualmente son los más resistentes a la acción de los diferentes agentes, estos son los restos craneales (dientes especialmente) y los apendiculares distaies (falanges y metápodos). De esta manera casi todas las excavaciones anteriores a los años 70 , reflejan una representación esquelética compuesta principalmente de elementos craneales y apendiculares distales, tal y como han apuntado Marean (1998), Marean y Kim (1998), Marean y Assefa (1999) para algunos yacimientos europeos e Yravedra (2001) para otros españoles. Esto se debe también a que las inquietudes zooarqueológicas de aquellos momentos sólo estaban relacionadas con el reconocimiento taxonómico y las posibles implicaciones paleoclimáticas y paleoecológicas de la fauna representada (Freeman 1973; Straus 1977), lo que influía en una recogida sesgada de los elementos anatómicos.

Por otro lado destacar la acción destructiva de los carnívoros. Los diferentes estudios zooarqueológicos y etnoarqueológicos que hay sobre estos taxones coinciden en mostrar sus preferencias por aquellos elementos óseos ricos en contenido graso, como son los elementos axiales, los huesos planos (escápula y pelvis) y las epífisis de los restos apendiculares, lo que tiende a dejar una sobrerrepresentación de dientes, pequeños fragmentos diafisiarios y metápodos, que por su menor contenido graso y su gran dureza los hace poco apetecibles. 
La subsistencia en el Pleistoceno Superior de la Península lbérica: problemas...

Tras esto, todo parece indicar que no hay una metodología óptima capaz de hacer inferencias sobre el orden de adquisición a los recursos cárnicos, sin embargo, los patrones de alteración ósea permiten reconstruir la historia tafonómica, saber qué agentes han actuado sobre las acumulaciones óseas y con qué intensidad lo han hecho. Por desgracia este tipo de análisis sólo se han empezado a aplicar en los últimos años y, para el caso de nuestro país el número de yacimientos estudiados es bastante escaso (tabla 2).

Partiendo de todas estas limitaciones y otras, como los diferentes planteamientos metodológicos e interpretativos de los distintos autores y las particularidades de cada asentamiento, se ha desarrollado un análisis bibliográfico de los estudios zooarqueológicos realizados en la Península lbérica. Para ello se ha analizado un conjunto superior a 150 yacimientos y 400 niveles, con el objeto de alcanzar algunas conclusiones interpretativas que deberán contrastarse en futuros trabajos.

Tabla 2. Yacimientos con estudios tafonómicos del pleistoceno superior de la Península Ibérica

\begin{tabular}{l|l|l}
\hline YACIMIENTOS & PERIODOS & REFERENCIA \\
\hline MOROS DE GABASA & MUSTERIENSE & Blasco (1995, 1997) \\
MORÍN 17 & MUSTERIENSE & Martínez (1998) \\
PENDO XVI & MUSTERIENSE & Martínez (1998) \\
LEZETXIKI VI & MUSTERIENSE & Martinez (1998) \\
COVA NEGRA & MUSTERIENSE & Martínez Valle (1996); Pérez Ripoll (1977) \\
COVA BENEITO & MUSTERIENSE & Martínez Valle (1996) \\
ABRIC ROMANÍ I & MUSTERIENSE-PAL.SUP-SOL. & Cáceres (1995, 1996 a; b) \\
COVA 120 & MUSTERIENSE & Rueda (1993) \\
MOLLETI & MUSTERIENSE & Rueda (1993) \\
L'ARBREDA & MUSTERIENSE & Rueda (1993) \\
CASTILLO & MUSTERIENSE-PAL.SUP-SOL & Pumarejo \& Cabrera (1992) \\
A'VALIÑA & AURIÑACIENSE & César Llama et alli (1991) \\
A'VALIÑA & AURINAACIENSE & Pumarejo \& Bernaldo Quiros (1990) \\
FUENTE DEL TRUCHO & PALEOLITICO SUPERIOR & Martínez (1993) \\
VILANOVA DE SAU & PAL. SUPER.MAGDALENIENSE & Vila \& Mitja (1987) \\
CUEVA AMBROSIO & SOLUTRENSE & Fernández Jalvo (en Ripoll 1988) \\
HIGUERAL DE MOTILLAS & SOLUTRENSE & Cáceres \& Ancoletani (1997) \\
PICAMOIXONS & MAGDALENIENSE & Perales \& Fernández. Jalvo (1990) \\
NERJA & MAGDALENIENSE & Morales \& Martínez (1995) \\
CENDRES & MAGDALENIENSE & Martínez Valle (1996) \\
BLAUS & MAGDALENIENSE & Martínez Valle (1996) \\
TOSSAL DE LA ROCA & MAGDALENIENSE-EPIPALEOL. & Pérez Ripoll (1992); Cacho et alli (1995) \\
EL CINGLE VERMELL & EPIPALEOLITICO & Vila \& Mitja (1985) \\
Paleolítico catalán & PAL. INFERIOR-SUPERIOR & Estévez (1979) \\
\hline
\end{tabular}


Para poder organizar la información se ha dividido la Península lbérica en tres áreas. En primer lugar está la cornisa cantábrica limitada por los Pirineos y los Picos de Europa. La segunda región es la mayor geográficamente y abarca la fachada atlántica y el interior peninsular. Por último está la vertiente mediterránea que ocupa una extensa franja extendida desde Gibraltar hasta el norte de Cataluña.

Junto a esta división geográfica se ha realizado otra cronológica, en la que se han diferenciado cuatro momentos asimilados a cuatro fases culturales, el Paleolítico Medio y el Musteriense, el Paleolítico Superior Inicial, distinguiendo Auriñaciense, Chatelperroniense, Perigordiense y Gravetiense, el Solutrense y el Magdaleniese (figura 1).

\section{LA SUBSISTENCIA EN LA PENÍNSULA IBÉRICA}

Antes de analizar cada momento de una manera más detenida, quiero referirme brevemente al panorama global de la representación taxonómica del Pleistoceno Superior de la Península lbérica tal y como lo observamos en las figuras 2-91.

Para la Cornisa Cantábrica (Figuras 2 y 3) la representación taxonómica está calculada en NISP y en MNI.

Aunque en el $M N /$ tiende a acrecentarse la proporción de aquellos taxones con menor número de restos, en el NISP y el MNI suele darse una tendencia similar. Si nos fijamos en la representación general de ambas figuras, se observa un equilibrio en los momentos iniciales del Musteriense y el Auriñaciense (1) y Perigordiense (1), que va cambiando según avanza el Paleolítico Superior, aumentando la proporción de determinados recursos (cérvidos y bóvidos pequeños). También son apreciables otras peculiaridades, como la drástica reducción de équidos y bóvidos desde el Auriñaciense (3) y el Perigordiense-Gravetiense (3), o la gran abundancia de bóvidos pequeños (cabras) en el PerigordienseGravetiense en contraposición a la abundancia de cérvidos en el

\footnotetext{
1 Para los taxones que aparecen en las giáficas se han distinguido: En primer lugar los carnívoros, incluyendo todo tipo de carnívoros, pero que en regiones como en Cataluña y la Cornisa Cantábrica está representada principalmente por los úrsidos. Entre los taxones «grandes» están incluidos la megafauna y los bóvidos especialmente, luego siguen los équidos que aunque es una especie de tamaño medio sus particularidades adaptativas lo diferencian del resto de los animales de tamaño medio, entre los que destacan principalmente los cérvidos. Finalmente las especies «pequeñas», están representadas por cabra y rebeco.
} 


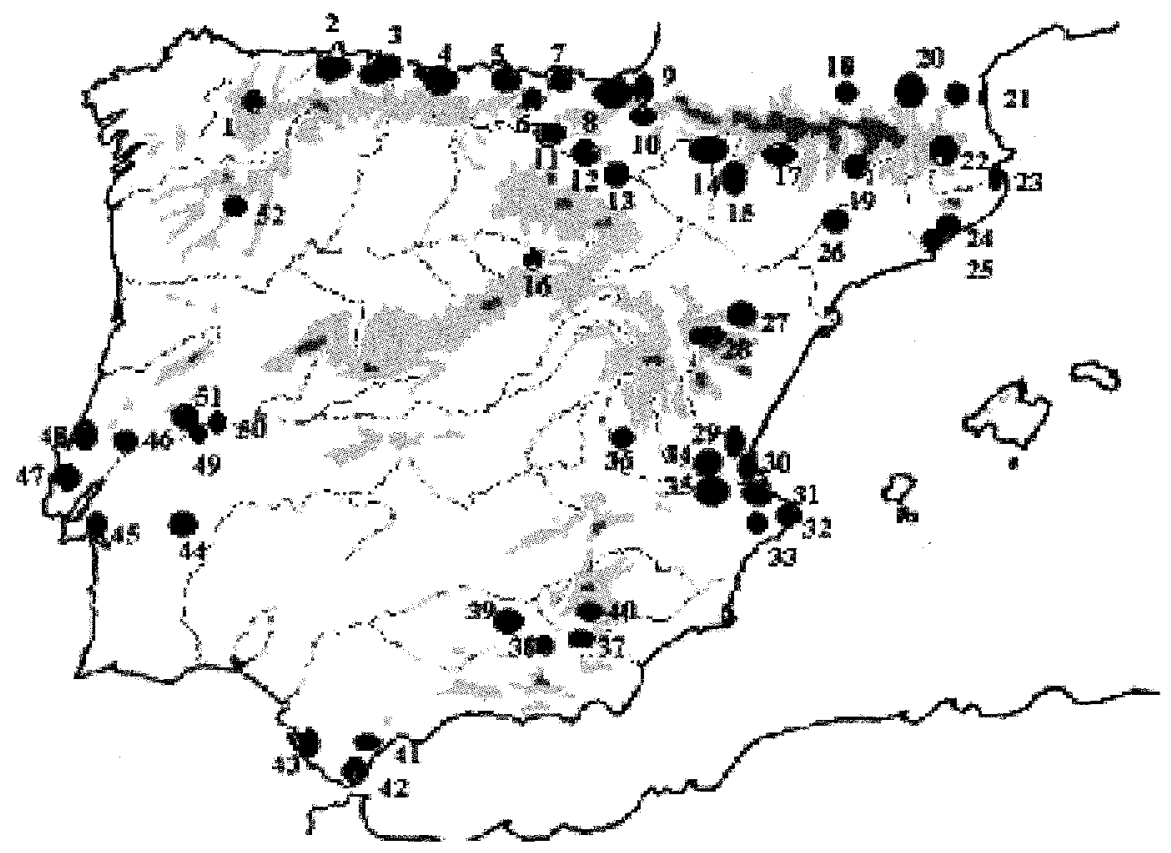

Fig. 1. Yacimientos de la Península lbérica tratados en el texto. A'Valiña (1), las Caldas, la Lluera, la Paloma y Sofoxó (2), Balmori, Buxu, Cierro, Coberizas, Conde, Cueto de la Mina, Collubil, la Lloseta, Cueva Oscura, Cueva Rosa, la Riera y Tito Bustillo (3), Altamira, Chufin, Castillo, Hornos de la Peña, el Juyo, el Mirón, Morín, Otero, la Pasiega, el Pendo, Rascaño (4), Axlor, Atxeta, Santimamiñe (5), Bolinkoba (6), Lamiñac y Lezetxiki (7), Amalda, Ekain,

Ermittia, Erralla, Urtiaga, Zatoya (8), Aitzbitarte N (9), Abauntz (10), Prado Vargas y

Valdegoba (11), Ermitia y Millan (12), Peña Miel (13), Chaves, Cova del Parco y Fuente del Trucho (14), Los Moros de Gabasa y los Toros (15), los Casares (16), Muricecs y L'Estret de Tragó (17), Cova 120, Els Ermitons (18), Toll y Teixoneres (19), L'Arbreda y Mollet (20), Cau del Duc de Torroella y Villanova de Sau (21), Castell sa Sala, Roc de la Melca, Bora Gran d'en Carreras (22), Cau de Coçes (23), Abric Romaní (24), Gegant y Muscle (25),

Pikamoixons (26), San Anton (27), Fuente de San Luis (28), Matutano (29), Blaus (30), Bolomor, Mallaetes, Parpalló y Volcán del faaro (31), les Cendres (32), Ratlla del Bubo (33), Cova Negra (34), Cova Beneito, Salt, Tossaal de la Roca, MoliMató (35), Verdelpino (36), Cueva Ambrosio (37), Cueva Horá (38), Boquete de Zafarraya (39), Cariguela (40), Nerja (41), Gorham's Cave, Devil's Tower (42), Higueral de Motillas (43), Escoural (44), Figueira Brava (45), Columbeira (46), Prado des Salemas y Gruta des Salemas (47), Lupa de Rainha y Furinha (48), Fontainhas (49), Fox de Exanrrique (50), Caldeirao (51), Lago Do Mine (52).

Auriñaciense, que puede explicarse por la particularidad de los propios yacimientos analizados, pues la mayoría de los niveles auriñacienses tratados pertenecen al Pendo y cueva Morín, frente a los perigordiensesgravetienses correspondientes a medios más escarpados y montañosos como indican Amalda, Lezetxiki y Bolinkoba, aunque la estación de 




Fig. 2. Patrones de Representación Taxonómico según el NISP de la cornisa cantábrica.



Fig. 3. Patrones de Representación Taxonómica según el MNI de la cornisa cantábrica. 
Labeko Koba supone una excepción, al no estar casi representados estos animales. Por otro lado, entre los niveles perigordienses de cueva Morín y el Pendo a diferencia de los auriñacienses, sí presentan restos de cabra aunque en proporciones muy bajas, pero parecen denotar esta tendencia de mayor proporción de cabra o rebeco en los niveles gravetienses-perigordienses que en los auriñacienses.

En la región mediterránea, se observa una altísima proporción de recursos secundarios, especialmente de lagomorfos, sobre todo en las zonas de Andalucía y el País Valenciano (figuras 4-5-8-9).

En cuanto a la macrofauna hay una tendencia muy similar a la descrita para la Cornisa Cantábrica. Se produce una representación taxonómica bastante equilibrada en el Musteriense que va cambiando según avanza el Paleolítico Superior. De esta manera nos encontramos en Cataluña un aspecto diversificado durante el Musteriense con gran abundancia de carnívoros, que tiende a cambiar en el transcurso del Paleolítico Superior hacia una mayor representación de équidos y cérvidos (figura 6-7). Lo mismo ocurre en Andalucía donde la especialización va encaminada hacia los cápridos y en el País Valenciano hacia cabra y ciervo (figuras 4-5).



Fig. 4. Patrones de Representación Taxonómico según el NISP del País Valenciano con lagomorfos. 


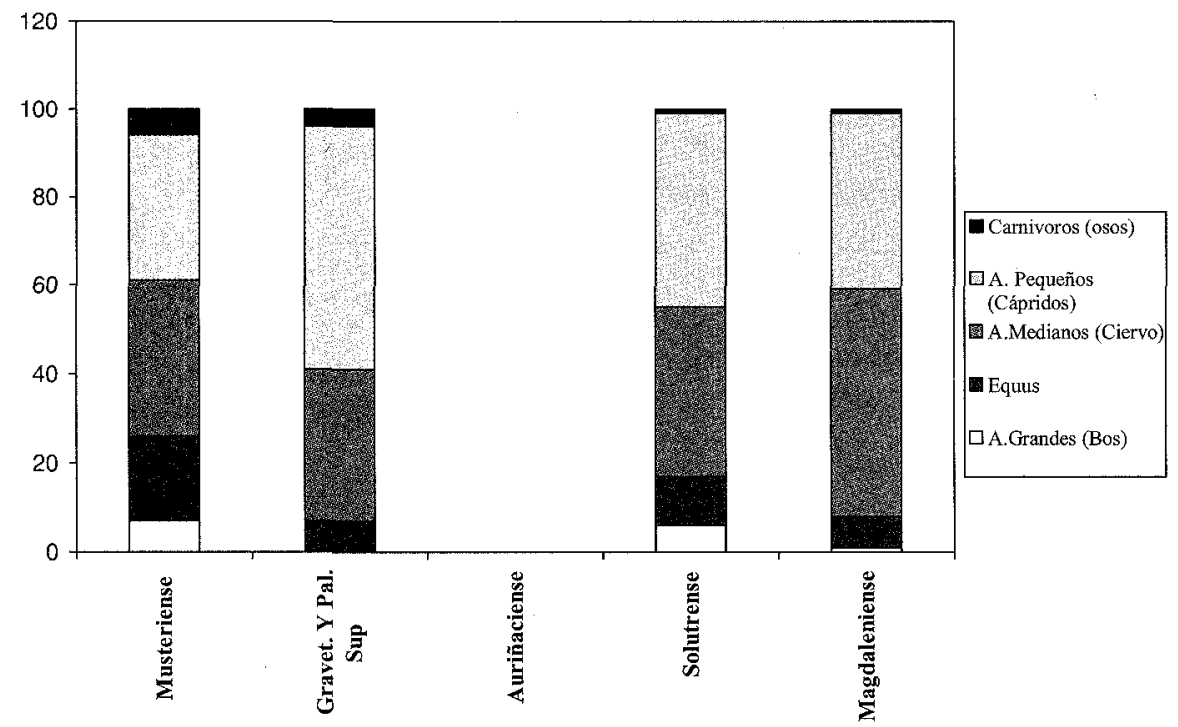

Fig. 5. Patrones de Representación Taxonómico según el NISP del País Valenciano sin lagomorfos.

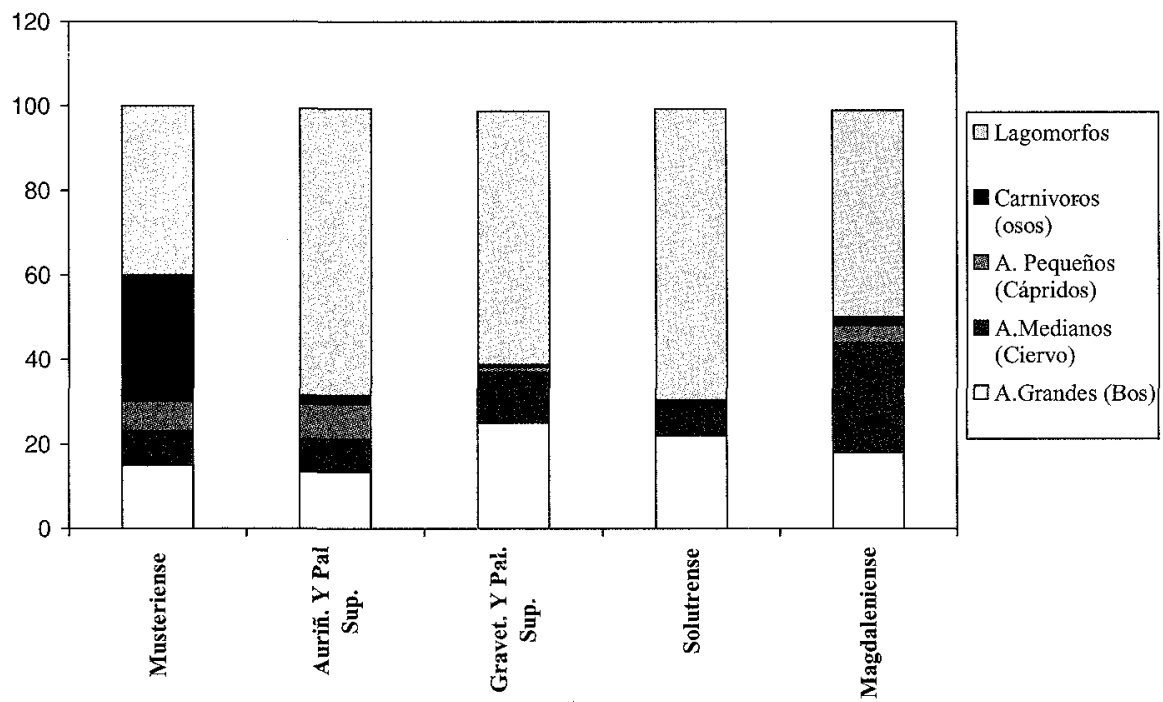

Fig. 6 Patrones de Representación Taxonómico según el NISP de Cataluña con lagomorfos. 


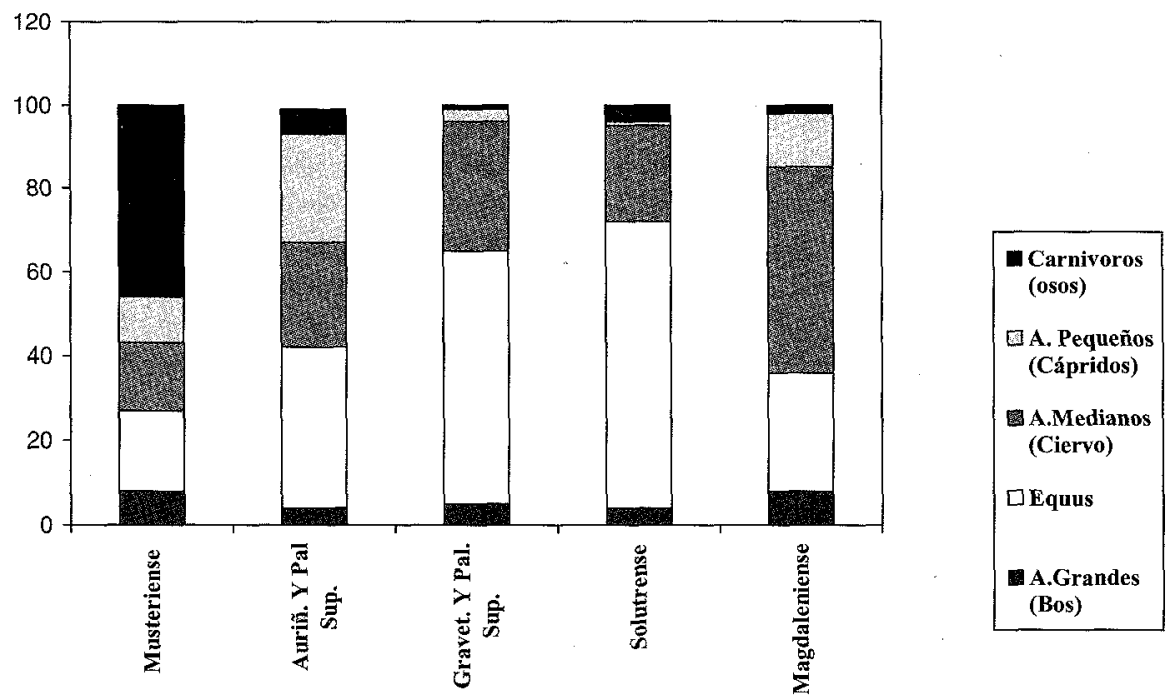

Fig. 7. Patrones de Representación Taxonómico según el NISP de Cataluña sin lagomorfos.



Fig. 8. Patrones de Representación Taxonómico según el NISP de Andalucía con lagomorfos. 




Fig. 9. Patrones de Representación Taxonómico según el NISP de Andalucía sin lagomorfos.

\subsection{Musteriense}

Respecto a los otros momentos que se van a analizar, este es el periodo del que se dispone de una información más equilibrada, debido a que muestra un conjunto de yacimientos bastante compensado en todas las regiones. Para la Cornisa Cantábrica se han analizado 6 estaciones y 22 niveles, para el Interior y la Fachada Atlántica 18 yacimientos y 25 estratos y para el ámbito mediterráneo 21 sitios y 60 niveles. En conjunto puede parecer una representación muy dispar, pero en comparación a los otros momentos, la información es bastante homogénea. Así, en los otros periodos tiende acrecentarse la proporción de datos de la Cornisa Cantábrica en contraposición a la del Mediterráneo, y frente a los 15 yacimientos y 36 niveles cantábricos del Paleolítico Superior Inicial, contrastan las 9 estaciones y 16 unidades mediterráneas aumentando aún más las diferencias durante el Magdaleniense y el Solutrense. Esta diferenciación contrasta más si se compara con los yacimientos del interior de la Península lbérica, los cuales casi no se han estudiado durante el Paleolítico Superior.

En el Musteriense se produce un patrón de representación taxonómica bastante diversificado, en el que todos los taxones (bóvidos, équidos, cérvidos y cápridos) están bien representados, pero en el que bóvidos y équi- 
dos fueron estos los principales aportes cárnicos como indica su mayor talla.

Si se analiza la representación taxonómica de cada yacimiento, se observa un patrón de representación bastante diversificado en el MNI. En el NISP se produce algo similar pero en algunos niveles de Axlor, Lezetxiki, el Pendo, Cova 120, Els Ermitons y el Boquete de Zafarraya hay cierta especialización, pues determinadas especies superan el $70 \%$ de los restos (Altuna 1972, 1980; Estévez 1979; Fuentes 1980; Barroso et alli. 1983; Torti 1983).

Por otro lado, algunos de los animales representados en ciertas estaciones no obedecen exclusivamente a un aporte antrópico. Los estudios tafonómicos de los Moros de Gabasa (Blasco 1995, 1997), Cova 120 (Rueda 1993), el Abric Romaní (Cáceres 1995, 1996 a, b), Cova Negra o Cova Beneito (Martínez Valle 1996) indican que la acumulación de cabra o rebeco se deben más a un aporte de cánidos que a otro humano.

De igual forma, estos mismos estudios tafonómicos han observado un importante acceso cárnico antrópico sobre los otros taxones y, así se aprecia un predominio de marcas de corte sobre los elementos apendiculares

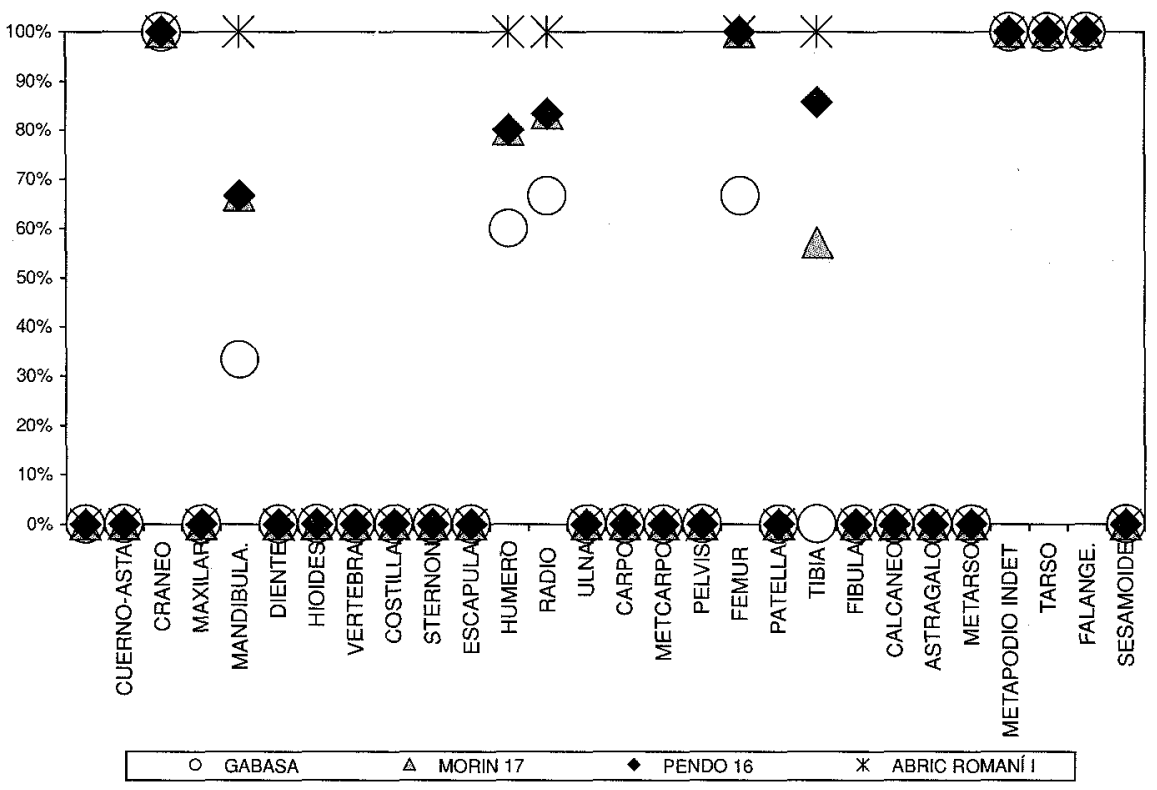

Fig. 10. Marcas de Corte en Equus. 
de mayor contenido cárnico (figuras 10, 11 y 12), lo que indica un acceso primario sobre las presas, pues en un consumo secundario dichas alteraciones antrópicas no tendrían lugar.

Junto a este acceso cárnico la fragmentación de los conjuntos óseos es superior a la de los siguientes momentos del Paleolítico Superior (Altuna 1972, 1986, 1990; Martínez Valle 1996; Villaverde y Martínez Valle 1992, 1995), lo que junto a las marcas de percusión indican un importante aprovechamiento medular.

Estos mismos estudios tafonómicos han indicado que el acceso que tuvieron los carnívoros sobre los équidos, bóvidos y cérvidos fue posterior a la acción humana. Así, se han documentado superposiciones de marcas de diente sobre marcas antrópicas y coprolitos sobre hogares (Cáceres 1995).

Entre los carnívoros, la ausencia de alteraciones antrópicas revelan que su presencia se debe a episodios de muerte natural. De esta forma la gran cantidad de restos de oso en Lezetxiki, Amalda, Cova 120, Els Ermitons y L'Arbreda son consecuencia de episodios de hibernación (Altuna 1972, 1990; Estévez 1979; Rueda 1993). También es natural la presencia de otros carnívoros en los Casares, los Moros de Gabasa,



-D-GABASA $\triangle$ MORIN 17 PENDO 16 \% ABRIC ROMANÍ

Fig. 11. Marcas de Corte en Ciervo. 


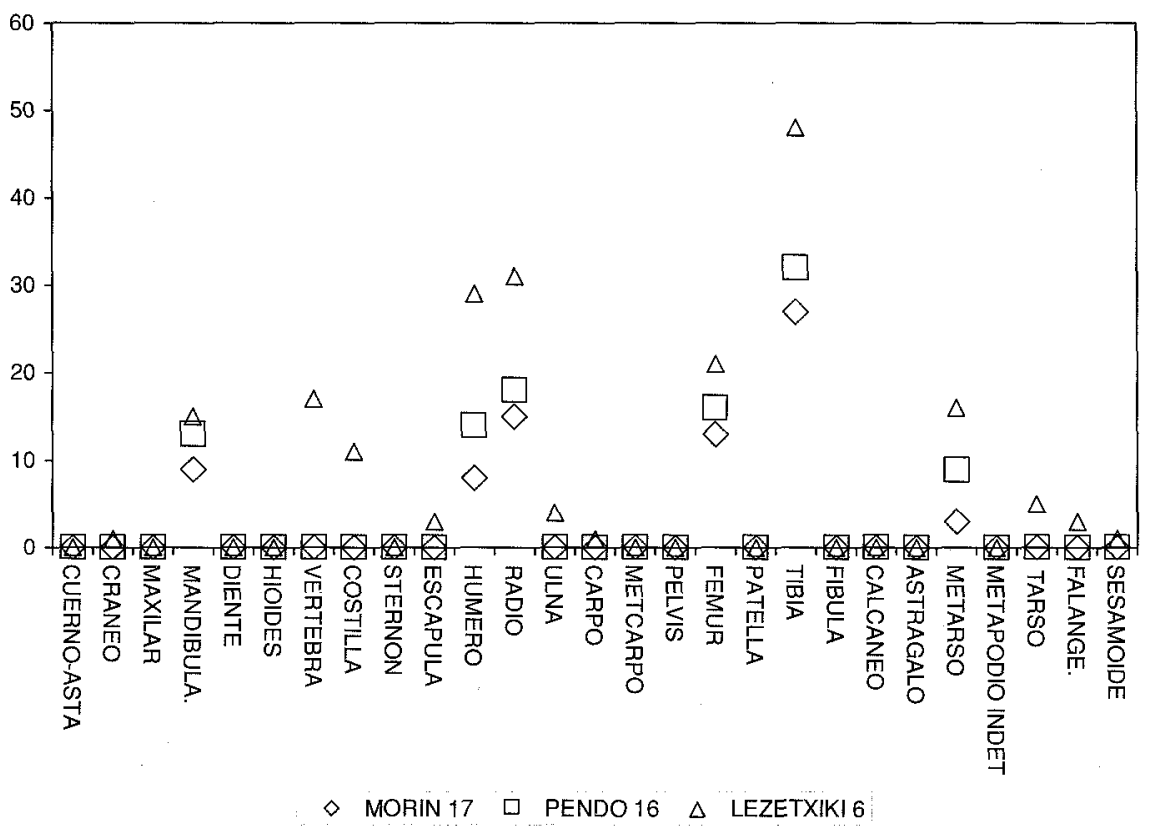

Fig. 12. Marcas de Corte en Bos.

Cova Negra, etc. (Altuna 1973; Pérez Ripoll 1977; Blasco 1995, 1997; Martínez Valle 1996). En el caso de los animales de pequeño tamaño, como son los lagomorfos, los estudios tafonómicos de Pérez Ripoll (1977) y Martínez Valle (1996) indican que su acumulación responde a un origen natural, bien como consecuencia de una mortandad natural en el interior de sus madrigueras, o como presas de carnívoros y aves (Pérez Ripoll 1977; Villaverde y Martínez Valle 1992, 1995; Martínez Valle 1996). Todo esto revela cierta alternancia en la ocupación de los asentamientos.

\subsection{Paleolítico Superior Inicial}

Como en el Musteriense, también se produce un patrón de ocupación alterno de los asentamientos, ya que los carnívoros siguen siendo importantes actores en A'Valiña, Ekain, Lezetxiki, Bolinkoba, Amalda, Fontainhas, etc. (Altuna 1972, 1990; Altuna y Mariezkurrena 1984; Llama 
et alli. 1991; Cardoso 1993; Rueda 1993; Martínez Valle 1996). Aunque en ocasiones como en Cova Beneito se han documentado marcas de corte sobre restos de lince (Villaverde y Martínez Valle 1995; Martínez Valle 1996), por lo que el aporte de estos taxones también obedece en algunos casos a un protagonismo antrópico. Igual ocurre con los lagomorfos y otros animales de pequeño tamaño que a diferencia de otras épocas ahora presentan abundantes marcas de corte (Martínez Valle 1996).

Frente a esta sutil diferencia respecto al Musteriense, todo lo demás indica cierta continuidad. Así, en las fases iniciales de este momento (Auriñaciense y Perigordiense 1 cantábrico ${ }^{2}$ ) hay una tendencia parecida al Musteriense, con gran abundancia de carnívoros, sobre todo en el Perigordiense y cierto equilibrio entre los distintos taxones, aunque en el Auriñaciense tienden a predominar los cérvidos y équidos (figuras 2 y 3 ). Pero según avanza el Paleolítico Superior Inicial en las otras dos fases, se observa cómo disminuyen drásticamente pero de manera progresiva bóvidos y équidos, al tiempo que aumentan en similar proporción los cérvidos en el Auriñaciense y los cápridos en el Perigordiense-Gravetiense (figuras 2 y 3). Hay que señalar que esta diferenciación de cérvidos (auriñaciense) y cápridos (perigordiense-gravetiense) obedece más a criterios geográficos que culturales, aunque es verdad que la proporción de cápridos en niveles perigordienses de Pendo o cueva Morín suele aumentar respecto a sus homónimos auriñacienses (Altuna 1971; Fuentes 1980).

En la región mediterránea el escaso número de yacimientos no permite alcanzar muchas conclusiones, pero parece producirse el comienzo de una tendencia con continuidad en las siguientes fases del Paleolítico Superior, encaminada hacia una futura especialización sobre determinados recursos. Al mismo tiempo, esta representación taxonómica refleja cierta similitud respecto al Musteriense. En la región valenciana-alicantina no parecen darse grandes diferencias, sólo aumentan los cérvidos y cápridos (figuras 4 y 5). En Cataluña hacen lo mismo los équidos y cérvidos de manera progresiva manteniendo en el caso del Auriñaciense un patrón de representación algo diversificado, dada la gran abundancia de cápridos (figuras 6 y 7). Finalmente en Andalucía los pocos conjuntos analizados (Gorham's Cave y Nerja) indican un claro predominio de cabra (figuras 8 y 9 ).

\footnotetext{
2 Esta asimilación, no obedece a un patrón de clasificación industrial, sino que se refiere a una diferenciación cronológica, en la que se diferencian tres fases. La primera abarca el 40000 $28000 \mathrm{BP}$, la segunda el $28000-25000 \mathrm{BP}$ y la tercera el $21000-18000 \mathrm{BP}$ (Yravedra 2000).
} 
En el aspecto particular de cada yacimiento, hay un patrón de consumo diversificado tanto en el MNI como en el NISP, ya que no suele superarse el $65 \%$ de los restos o de los individuos. Aunque algunos niveles de Pendo, cueva Morín, Santimamiñe, Mallaetes, Fuente del Trucho o L'Arbreda sí alcancen este promedio en el NISP y en algún caso también en el MNI.

Esta continuidad con respecto al Musteriense también queda definida en el patrón de capturas, ya que como revelan los diferentes estudios zooarqueológicos, se prefieren los individuos adultos, tal y como ocurría en aquel periodo, aunque ahora la proporción de infantiles aumenta ligeramente. De la misma forma se mantiene la gran fragmentación de los conjuntos óseos, muy superior a la de los momentos solutrenses y magdalenienses, pero inferior a las del Musteriense.

\subsection{Solutrense}

La continuidad descrita en el tránsito del Musteriense al Paleolítico Superior Inicial y sus sucesivas fases llega ahora al Solutrense. En primer lugar continúa la progresiva disminución de la fragmentación de los conjuntos óseos, también lo hace el consumo de recursos "secundarios", destacando en este apartado el aporte antrópico de lagomorfos y por último se mantiene el predominio de adultos aunque se incrementa la proporción de infantiles respecto al momento anterior, algo que ya se produjo en dicho momento frente a su precedente.

En la representación taxonómica también se observa esta continuidad. Los carnívoros se reducen a una presencia marginal, manteniendo la tendencia de las últimas fases auriñacienses y perigordienses-gravetiense de progresiva reducción. Lo mismo ocurre con los équidos y bóvidos que ya mostraron su gran retroceso en aquellas fases. Tan sólo en Cataluña los équidos siguen bien representados siendo la especie más importante. Por otro lado, es apreciable una cierta especialización sobre cérvidos y cápridos que dependen de la situación de los yacimientos y las condiciones climáticas (Yravedra 2001). Esta relativa especialización ha sido identificada en la Cornisa Cantábrica por Straus $(1983,1992)$, Altuna (1994) y Quesada (1995, 1997 a, b, c) aunque esta debe matizarse, ya que alguno de estos autores como Altuna (1994) y Quesada (1997 b) diferencian dos fases. Una inicial de cierta diversificación y otra de progresiva especialización que comienza con los fríos del final del Interestadial Laugurie Lascaux. 
Para esta región se han analizado 23 yacimientos y 53 niveles, de los cuales 42 presentan unas muestras faunísticas representativas (Yravedra 2001). De ellos los cérvidos predominan claramente en 28 estratos, y alcanzan especialización en 16 tras superar el $65 \%$ de los restos. La cabra destaca en 12 niveles y presenta especialización en tres.

En el $M N /$ de esos mismos niveles, la especialización se limita a cuatro yacimientos (Riera, Cierro, Balmori y Cueto de la Mina), y sólo en 17, algún taxón sobrepasa el $50 \%$ de los individuos, por lo que la especialización del Solutrense es muy relativa.

Desde una perspectiva cronológico-cultural, apreciamos que hasta el Solutrense Superior hay especialización de cabra en Bolinkoba y Caldas 10, de ciervo en Lluera 9, Caldas 12, 13 y otra especialización relativa (en torno al $50 \%$ ) de cabra o ciervo en Ermittia y Riera 2-3. Aunque de estos, Ermittia y Lluera son problemáticos, debido a que en Ermittia se incluyen dos niveles y en Lluera sólo se ofrecen los porcentajes de los materiales que están en estudio por Altuna (Altuna 1994). A pesar de esta circunstancia parece haber una pequeña especialización en torno a un taxón en particular, pero hay pocos niveles que permitan confirmarlo.

Para el Solutrense Superior se puede observar una especialización sobre cabra, sarrio o ciervo según el NISP en todos los yacimientos a excepción de Aitzbitarte IV, el Buxu, el Castillo 10, Chufín a, b, Lluera 8 y Urtiaga. Lo que indica una especialización relativa de estas especies, ya que a excepción de los últimos niveles de la Riera no suelen sobrepasar el $65 \%$ de los restos. En el Solutrense final, como el Solutrense inicial y medio hay pocos niveles que nos indican un predominio de ciervo y sólo en algunos estratos alcanzan cierta especialización, aunque menor que la del Solutrense Superior, como indican Santimamiñe y Cueto de la Mina.

Así se puede apreciar un aprovechamiento bastante similar en el transcurso de todo el Solutrense. En cualquier caso las estrategias de acumulación tanto diversificadas como especializadas giran en torno a los condicionantes del medio y el clima. De esta forma los niveles de yacimientos sobre valle en momentos templados reflejaran una gran representación de cérvidos, en contraposición a los emplazamientos de media montaña, donde los cápridos son más abundantes. Al tiempo, que aquellos lugares de ámbito mixto como el Buxu, Urtiaga, Ermittia, Chufin y Aitzbitarte muestran diversificación.

En el Mediterráneo, el área del País Valenciano muestra un claro predominio de cérvidos y cápridos según la situación del yacimiento, continuando la tradición del periodo anterior. En Cataluña, continúa el panorama descrito durante el Paleolítico Superior Inicial, ya que siguen 
aumentando los équidos. Por último en Andalucía, se observa un predominio de cápridos y cérvidos similar al del Paleolítico Superior Inicial. Aunque en este caso el número de sitios estudiados es muy escaso.

\subsection{Magdaleniense}

Este momento como los anteriores mantiene cierta continuidad. Así, se incrementa el consumo de recursos secundarios (Clark y Yi 1983; Clark 1986), disminuye la fragmentación de los conjuntos óseos (Pérez Ripoll 1992) y aumentan los porcentajes de infantiles, aunque siguen siendo los adultos los mayoritarios.

Esta continuidad también queda reflejada en el predominio de cérvidos y cápridos, que se acrecienta todavía más en estos momentos, alcanzando la especialización en NISP y $M N I$ en bastantes yacimientos, aunque no en todos como indican Abaunitz, Caldas 1 y 2, Castillo, Ekain VI, Erralla 3-1, Lezetxiki, Santimamiñe 2-5, Urtiaga E y Riera 24 (Yravedra 2000).

Sobre esta especialización hay que destacar que en función del $M N /$ es bastante menos acusada que la descrita por el NISP, ya que tan sólo en 20 niveles de los 52 analizados supera algún taxón el $60 \%$ de los individuos. Todo parece indicar una especialización progresiva, en el que a medida que avanza el periodo aumenta el predominio de determinado taxón, lo que puede observarse en los sucesivos estratos de Tito Bustillo, la Riera o el Juyo (Gómez y Mejide 1975; Altuna 1986; Barandiaran et alli. 1987).

Además, esta especialización según el NISP sobre ciervo o cabra, esta claramente ligada al entorno circundante de los asentamientos y las condiciones climáticas, aunque en condiciones adversas parecen observarse ciertas preferencias por los cérvidos, pues algunos lugares muestran un predominio de este taxón en momentos climáticos y medios geográficos más favorables para la cabra. De esta forma, lugares como Tito Bustillo o el nivel 24 de la Riera indican cierta especialización sobre ciervo, en momentos fríos y en nichos próximos a lugares montañosos. Pero si este ejemplo no es muy bueno por la cercanía al mar de estos dos sitios, en otros casos de biotopos mixtos e incluso algo escarpados y en momentos frios que pudieron favorecer la abundancia de Capra pyrenaica o Rupicapra rupicapra, aparece muy bien documentado el ciervo, alcanzando la especialización en niveles como los de Ekain VII o Zatoya, y en otros casos como Abauntz, el ciervo está muy bien documentado a pesar de la rigurosidad climática. Por lo que la especialización se centra en el ciervo y sólo en aquellos lugares totalmente adversos a este taxón se producirá sobre los cápridos. 
En los niveles de la región mediterránea, se observa una tendencia similar de especialización sobre determinados recursos, condicionadas por el medio, el clima y las propias preferencias humanas. En los seis yacimientos analizados en Cataluña, L'Arbreda, Castel sa Sala, Bora Gran d'en Carreras, Vilanova de Sau, Pikamoixones y Roc de la Melca hay un predominio de équidos y cérvidos, a pesar de que algunos de estos sitios son más favorables para la cabra como Vilanova de Sau, Pikamoixones o Castell Sa Sala.

Los dos yacimientos andaluces analizados (Gorham's Cave y Nerja) muestran un predominio de cabra a pesar de la proximidad de la costa y las condiciones templadas de algunos de los niveles, lo que puede indicar ciertas preferencias por este taxón.

Finalmente en la región del País Valenciano, no parece haber esta especialización preferencial, ya que el predominio de unos u otros taxones está ligada claramente al medio. Así, en yacimientos de interior como el Tossal de la Roca priman los cápridos (Cacho et alli. 1995), y en otros de costa como Les Cendres (Villaverde et alli. 1997) lo hacen los cérvidos, de la misma manera que en otros lugares abiertos a multitud de posibilidades como Matutano (Olaria et alli. 1981), está uno u otro taxón según varíen las condiciones climáticas.

En resumen es apreciable cierta especialización de carácter preferencial sobre los cérvidos y équidos en Cataluña, sobre la cabra en Andalucía y, sobre los cérvidos en la cornisa cantábrica, aunque también habría especialización sobre los cápridos en los lugares donde las condiciones climáticas obligaran a ello. Por lo que los condicionantes del medio y el clima siguen siendo importantes, pero por primera vez aparece un criterio selectivo en el régimen de las capturas que no se deben principalmente al entorno, aunque en el caso del País Valenciano esta dependencia es más acusada.

\subsection{Recapitulación}

Se puede observar un patrón de subsistencia marcado por una gran continuidad gradual. De tal manera, que apenas se perciben diferencias entre unos momentos y otros. Así, en la transición entre el Solutrense y el Magdaleniense apenas se producen divergencias y, entre el Paleolítico Superior Inicial y el Solutrense tampoco. Sólo en algunos casos como es el paso del Auriñaciense-Perigordiense (1) al (2) aparecen unas diferencias algo mayores, igual que ocurre con el Musteriense y el Auriñaciense (1), 
pero en ninguno de los dos casos son significativas. Por lo que hay una evolución progresiva en las estrategias de subsistencia utilizadas en el transcurso del Pleistoceno Superior sin casi diferencias entre periodos, que sólo son importantes si se comparan dos momentos separados por un gran lapso temporal, como el Musteriense con el Solutrense o el Magdaleniense.

Además, desde un punto de vista cárnico, los estudios tafonómicos han mostrado como el patrón de consumo es similar en el Paleolítico Medio que en el Superior, ya que en todos los momentos se produce un importante acceso cárnico, sólo quizás a partir del Paleolítico Superior aumente de forma progresiva el consumo de los recursos secundarios y los carnívoros.

Finalmente decir que esta subsistencia va encaminada hacia una relativa especialización progresiva centrada en las especies de tamaño medio y pequeño (ciervos y cápridos), que acaban siendo los taxones principales del Solutrense y el Magdaleniense.

Volviendo al análisis de los patrones de representación anatómica, se ha de indicar que en todos los momentos predominan las secciones apendiculares distales y craneales, debido a los condicionantes indicados en el apartado dos, pero el promedio de elementos apendiculares proximales y axiales suele aumentar respecto al Musteriense y el Paleolítico Superior Inicial en el Solutrense para volver a disminuir en el Magdaleniense (figuras 13-16). Esto tiene una clara explicación, por un lado hay que destacar la alternancia que carnívcros y humanos generan en las ocupaciones de los asentamientos, lo que implica una profunda alteración del conjunto osteológico a cargo de los animales. En el Solutrense la ocupación de los emplazamientos se hace más sedentaria que en el Paleolítico Superior Inicial, lo que repercute en una incidencia menor de los carnívoros sobre el conjunto óseo. Además, influye también la desaparición de muchos de los grandes carnívoros (cuón, hiena, pantera), destacando sobre todo la desaparición de las hienas que son los principales carroñeros. Estos dos factores explican la mejor conservación de los elementos axiales y los apendiculares proximales. Por último esta tendencia continúa en el Magdaleniense, sin embargo, el desarrollo del arte mueble y el aprovechamiento de la grasa de las epífisis y el esqueleto axial repercute en una peor conservación de estos elementos frente a otros más resistentes (tabla 3).

Otros factores que influyen es la disminución de la fragmentación de los conjuntos óseos desde el Paleolítico Superior (Altuna 1972; Pérez Ripoll 1992; Rueda 1993; Martínez Valle 1996), lo que facilita la conservación y la mejor identificación de los conjuntos óseos. Relacionado con esta menor fragmentación está el progresivo incremento de infantiles en la representación taxonómica, que aunque siempre predominen los adultos, es apre- 
Tabla 3. Condicionantes que influyen en los Patrones de Representación Anatómica



ciable un aumento progresivo de los individuos deciduales según avanza el Paleolítico Superior Inicial. Estos especímenes al carecer de médula sufren una fracturación menor que los adultos $\mathrm{y}$, por tanto, reducen la fragmentación de los conjuntos. De la misma manera, la reducción progresiva de la talla de las especies consumidas, tiende también a reducir la fragmentación, pues las especies de mayor tamaño tienen una fracturación mayor que la de los animales de menor talla (Klein 1989; Bartran 1993; Marean 1998) y, como se ha visto, según avanza el Paleolítico la presencia de cérvidos y cápridos aumenta en contraposición a la reducción de bóvidos y équidos.

Pero el principal factor influyente en esta representación anatómica más compensada es el acceso secundario de los carnívoros, el cual puede deberse a dos causas. Por un lado la extinción de algunos de estos taxones, como indica la casi ausencia de grandes carnívoros, en especial de hienas y grandes félidos, que sólo han sido identificados con un escaso número de restos en Algar do Casais, Bolinkoba, Castillo y Urtiaga para el Solutrense y en Abauntz, Castillo, Altamira, Bolinkoba, Juyo, Paloma, Rascaño y Urtiaga para el Magdaleniense. Por otro lado, otro factor influyente en esta menor acción de los carnívoros, pudo ser una ocupación 


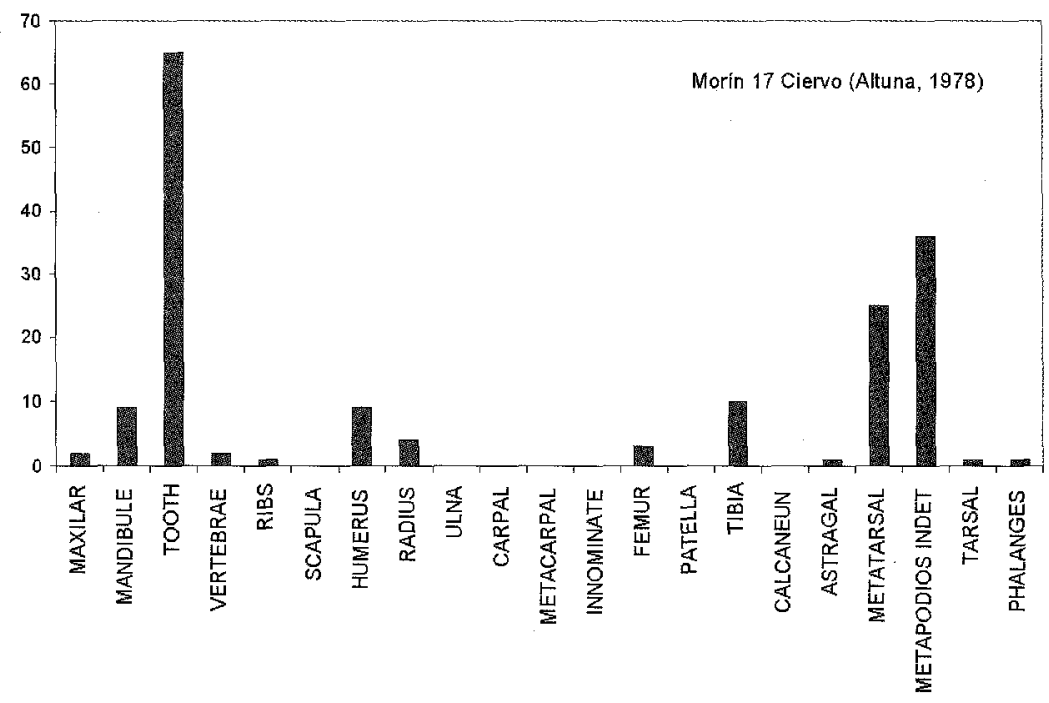

Fig. 13 Representación Anatómica en un nivel Musteriense. Ej. Morín 17.

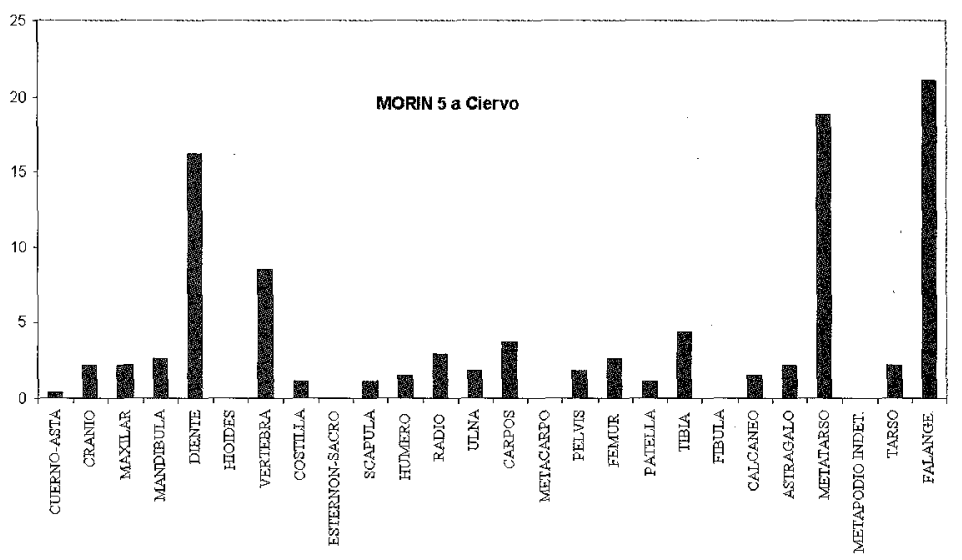

Fig. 14 Representación Anatómica en un nivel del Paleolítico Superior Inicial. Ej. Morín $5^{a}$.

antrópica de los asentamientos más prolongada como han indicado Altuna (1986, 1990), Straus (1992), Villaverde y Martínez Valle (1992, 1995), Quesada (1995, 1997 a, b, c) y Martínez Valle (1996). Esta acción antrópica más prolongada puede influir en una mayor alteración térmica de los restos óseos, como ha documentado Rueda (1993) y Martínez Valle 




Fig. 15 Representación Anatómica en un nivel Solutrense. Ej. Castillo 10.

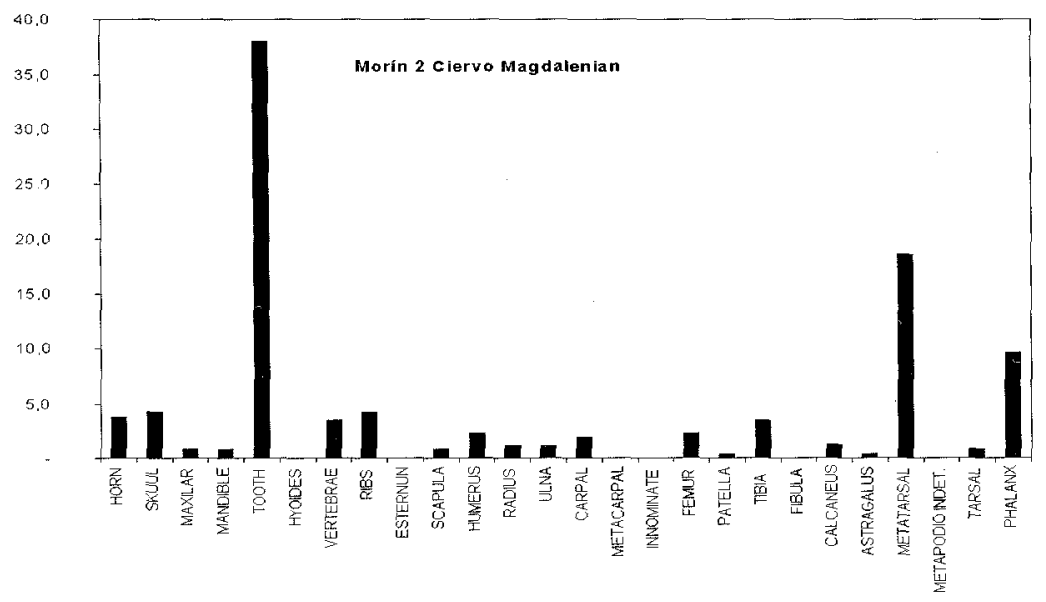

Fig. 16 Representación Anatómica en un nivel Magdaleniense. Ej. Morín 2.

(1996) qué puede influir en una mayor conservación de aquellos elementos ricos en grasa (epífisis y elementos axiales), pues al estar quemados son menos atractivos para los carnívoros (Domínguez Rodrigo 1998).

Otro factor influyente en la sesgada representación anatómica es el momento en el que se realizaron las excavaciones y los análisis de los 
conjuntos óseos. Así, todos aquellos yacimientos estudiados en fechas anteriores a los años 70, muestran un predominio de segmentos craneales y apendiculares distales, lo que contrasta con aquellos niveles estudiados en fechas recientes o analizados por zooarqueólogos como el Abric Romaní (Cáceres, 1995, 1996 a, b), Matutano (Olaria et alli 1981, 1997; la Riera (Altuna 1986), Amada (Altuna 1990), Fuente del Trucho (Martínez Moreno 1993), Lamiñac (Castaños 1988), Zatoya (Barandiarán \& Cava 1989), Tito Bustillo (Gómez Fuentes \& Mejide 1975), o Erralla (Altuna et alli 1985), donde aumentan los porcentajes de elementos apendiculares proximales y axiales.

Tras todos estos factores no se puede realizar ninguna precisión clara sobre los patrones de representación anatómica, ni las pautas de transporte, ya que son varios los factores que influyen de manera definitiva sobre tal representación.

\section{CONCLUSIÓN}

Como se ha podido intuir a lo largo de este trabajo, las conclusiones a las que se llega no pueden ser muy positivas, ya que el panorama zooarqueológico parte de bastantes limitaciones. A pesar de esto se ha intentado establecer una serie de precisiones a partir de los estudios faunísticos realizados, que deberán ser confirmadas en futuros trabajos más meticulosos, en los que primen un enfoque tafonómico.

Además, estas interpretaciones son discutibles pues se basan en los estudios a los que se hace referencia. De tal forma que en algunos casos se habla de posible especialización o diversificación de los recursos adquiridos por las poblaciones paleolíticas, pero, sin embargo, los trabajos a los que se hace referencia no cuentan con análisis tafonómicos que confirmen la primacía antrópica de dichas acumulaciones. Sólo algunos yacimientos del Paleolítico Medio y otros del Paleolítico Superior cuentan con estudios de este tipo, como se muestra en la tabla 2 y, en algunos de ellos se ha visto como la acumulación de cápridos en el Musteriense es consecuencia de episodios naturales de carácter biológico. Por poner un ejemplo, sería interesante hacer este tipo de análisis en las acumulaciones de cápridos de los yacimientos perigordienses y gravetienses cantábricos, pues cuentan con una gran representación de carnívoros que puede implicar algún tipo de relación.

Otro problema de los yacimientos analizados es que en muchos casos se refieren a lugares o niveles con muestras óseas poco representativas, 
de la misma forma que los análisis tafonómicos de Cova Negra o Cova Beneito, se hacen en función de un escaso NISP y un número de marcas muy escaso; por ello se deben realizar nuevos estudios con conjuntos más numerosos.

Por último, las correlaciones realizadas son también bastante limitadas, ya que tan sólo la región Cantábrica tiene una muestra de yacimientos abundante, pues las demás zonas y en especial el interior y la fachada atlántica, dada la escasez de estudios realizados no permite llegar a conclusiones significativas. Igual ocurre con las otras regiones de Andalucía o Cataluña cuyos análisis zooarqueológicos son escasos.

Finalmente en función de la información analizada, puede observarse que según el NISP hay cierta especialización progresiva iniciada en algunos niveles musterienses, que aumenta en el Paleolítico Superior Inicial, y se consolida en el Solutrense de forma relativa, para concluir en el Magdaleniense de una manera absoluta. En cambio en el MNI, sólo se alcanzará la especialización en el Magdaleniense, ya que en el Solutrense apenas se produce. Por lo que es importante usar unos mismos criterios interpretativos para obtener unas conclusiones más serias.

\section{BIBLIOGRAFIA}

Altuna, J. (1971): Fauna de Mamíferos del Yacimiento Prehistórico de Cueva Morín, Santander. Eri La Cueva Morín excavaciones 1966-68. (González Echegaray, J. y Freeman L. G). Publicaciones del Patronato Cuevas Prehistóricas de Santander 6: 367-398.

Altuna, J. (1972): Fauna de Mamíferos de los Yacimientos Prehistóricos de Guipuzcua. Munibe XXIV.

Altuna, J. (1973 a): Fauna de Mamíferos del Yacimiento Prehistórico de los Casares (Guadalajara). Excavaciones arqueológicas en España 76: 96-116.

ALTUNA, J. (1980): Fauna del Yacimiento de Axlor (Vizcaya) Vasconia antigua. Excavaciones en Axlor Obras completas 17 (J.M. Barandiaran).

AltunA, J. (1986): The Mammalian faunas from the prehistoric site of the Riera. The Riera Cave Stone age Hunter, garthener adaptation in Northern Spain (Straus, L.G y Clark). Antropological Research Papers Univ. Arizona 36.

AltunA, J. (1990): Caza y alimentación procedente de macromamíferos durante el Paleolítico de Amalda. En La cueva de Amalda (P.Vasco) ocupaciones paleolíticas y postpaleolíticas. (J. Altuna, A. Balderon y K. Mariezkurrena). Sociedad de Estudios Vascos serie B4: 149192.

AltunA, J. (1994): Los macromamíferos durante el Solutrense de la Península lbérica. Fervedes 1: $47-56$.

Altuna, J. y MariezKurRenA, K. (1984): Bases de subsistencia de origen animal en el yacimiento de Ekain (Deba Guipuzcua). Sociedad de estudios Vascos Serie B1: 211-280.

Altuna, J.; Baleron, A. y MARiezkurRena, K. (1985): Cazadores magdalenienses en Erralla. Munibe 37. Vol. 1-4.

BarandiaRAN, J. M. y CAVA A. (1989): El yacimiento prehistórico de Zatoya (Navarra). Trabajos de Arqueología de Navarra 8.

Barandiaran, J.M.; Freeman, L. G. y GonzÁlez Echegaray, J. (1987): Excavaciones en la cueva del Juyo. Monografías del Centro de Investigaciones y Museo de Altamira 14. 
Barroso, C.; Gracía, M.; Ruiz Bastos, A.; Medimacara, P. y Sanchidrian J. L. (1983): Avance al estudio cultural antropológico y paleontológico de la cueva del Boquete de Zafarraya. Antropología y Paleoecología Humana, 3: 3-12.

BARTRAM, L. E. (1993): Perspectives on skeletal part profiles and utility curves from Eastern Kalahari ethnoarchaeology. En Bones to behavior: Ethnoarchaeological and experimental contributions to the interpretations of faunal remains. J. Hudson (ed.) Southern Illinois University: 115-137.

Bartram, L. E. (1995): Etnoarqueología i ossos animals at Kalahari Oriental. Cota Cero 11: 38-50.

Bernaldo de Quirós, F. (1980): Notas sobre la economía del Paleolítico Superior Cantábrico. Centro de Investigaciones y Museo de Altamira, Memorias, Santander.

BinfORD, L. R. (1978): Nunamiut Ethnoarchaeology. New York, Academic Press.

BINFORD, L. R. (1981): Bones: ancient men, modern myths. New York, Academic Press.

BINFORD, L. R. (1984): Faunal Remains fron Kasius River Moupth. New York, Academic Press

BINFORD, L. R. y BERTRAM, J. B. (1977): Bone frequencies and attritional processes. For theory Building in Archaeology. Binford, L.R. (ed.).

Binford, L. R. y StOne, N. M. (1986). Zhoukoudian: A closer loock. Current Anthropology 27 (5): 453-475.

BLASCO Sancho, M. F. (1995): Hombres, fieras y presas, estudio arqueológico y tafonómico del yacimiento del Paleolítico Medio en la cueva de los Moros de Gabasa 1 Huesca. Universidad de Zaragoza.

BlAsco SANCHO, M. F. (1996): Sobre la aplicación del índice tafonómico (carnívoros/ungulados) en los conjuntos de fauna prehistórica. Comunicación de la ll reunión de tafonomía y fosilización, Madrid, 1996: 55-60.

Blasco Sancho M. F. (1997): Cave site of Gabasa in the Spanish Pyrinees. Journal of Antropological Research 53: 177-218.

CÁCERES, I. (1995). Estudios tafonómicos de los procesos de formación del Nivel i del Abric Romani (Capalledes Barcelona). La Influencia de la actividad antrópica. Tesis de Licenciatura. Departamento de Historia y Geografía. Facultad de Letras. Universidad Rovira i Virgili (Inédita).

CÁCERES, I. (1996 a): Secuencia de los procesos y mecanismos de alteración de la asociación fósil de macromamíferos del Nivel I del Abric Romaní (Capalledes Barcelona). Comunicación de la ll reunión de Tafonomía y Fosilización 1996: 73-78

CÁceres, I. (1996 b): Taphonomic Processes in the Level I. Abric Romaní. (Barcelona, Spain). En III Internationall congress of prehistoric and protohistoric sciencies. Forli 2 : 381-386.

CÁceres, I. y Anconetani, P. (1997): Procesos tafonómicos del nivel Solutrense de la Cueva de Higueral de Motillas (Cádiz). Zephyrus 50: 37-50.

Cacho Quesada, C.; Fumanal, M.P; López, P.; López, J. A.; Pérez Ripoll, M.; Martinez Valle, R.; Uzquiano, P.; Arnanz, A.; Sánchez A.; Sevilla, P.; Morales, A.; Roselló, E.; Garralda, M. D. y García-CARRILlo, M. (1995): El Tossal de Alcoy reconstrucción paleoambiental y cultural de la transición del tardiglaciar al Holoceno inicial. Recerques del Museo de Alcoy 4: 11-101

CARdoso, J. L. (1993): Contribuçao para o Conhecimiento dos grandes Mamíferos du Pleistoceno Superior de Portugal. Comarca Municipal de Oeiras.

Castaños, P. (1988): Estudio de los macromamíteros de Lamiñak II. Kobie 17: 12-94

CLARK, G. A. (1986): El nicho alimenticio humano en el Norte de España desde el Paleolítico hasta la Romanízación. Trabajos de Prehistoria 63: 159-184.

ClARK, G. A. y Y., S. (1983): Niche Width variation in Cantabrian archeofaunas: A diacronic study. En Animals and Archaeology. The Hunters and their prey (Clucton Brock, J.; Grigson, C. ed.). British Archaeological Reports (BAR) 163:183-209.

CRADER, D. (1983): Recent single-carcass bone scatters and the problem of butchery sites in the archaeological record. En Animals y Archaeology: Hunters and their prey British Archaeological Reports (BAR) 283: 107-142.

DiEZ, J. C. (1992): Zooarqueología de atapuerca (Burgos), e implicaciones paleoconómicas del estudio tafonómico de yacimientos del Pleistoceno Medio. Tesis Doctoral. Universidad Complutense de Madrid.

Díez, J. C; Moreno, V.; Rodríguez, J; Rosell, J. y CÁceres, I. (1999): Estudio arqueozoológico de los restos de macrovertebrados de la Unidad III de Galería. En Atapuerca. Ocupaciones 
humanas y paleoecológicas del Yacimiento de Galería. Arqueología de Castilla y León. Carbonell, E.; Rosas González, A.; Díez, J. C. (ed.): 265-281

Domínguez Rodfigo, M. (1996): Caza y Carroñeo: Reflexiones en torno a la validez de las diagnosis aplicadas al registro arqueológico. Tabona IX: 273-298.

Dominguez RodRigo, M. (1998): Estudio del conjunto óseo de un asentamiento de cazadores furtivos, Mwalangulu en Galana (Kenya). Complutum 9: 161-166.

Domínguez Rodrigo, M. (1999): The study of skeletal part profiles: An ambigous taphonomic tool for Zooarchaeology. Complutum 10: 15-24.

Estévez, J. (1979): La Fauna del Pleistoceno catalán. Tesis doctoral inédita. U. A. de Barcelona.

EstÉVEZ, J. (1980): Aprovechamiento de recursos faunísticos, aproximación a la economía del Paleolítico catalán. Cypsela 3: 9-30.

Freeman, L. G. (1973): The significance of mammalian faunas from Paleolithic occupations in Cantabrian Spain. American Antiquity 38 (1): 3-44.

Fuentes Vidarte, C. (1980): Estudio de la Fauna del Pendo. En El Yacimiento de la Cueva del Pendo excavaciones 1953-57. González Echegaray, J. (ed.) Biblioteca Prehistórica Hispana 17: 215-238

GÓMEZ FUENTES Y MEJIDE (1975): Fauna de Tito Bustillo. En Primeros sondeos estratigráficos en la cueva de Tito Bustillo (García Guinea, M).

González Echegaray (1980): El Paleolítico Superior de la cueva del Pendo, excavaciones 195357. Monografías del Centro de Investigación de Altamira 3.

HILL, A. (1975): Taphonomy of contemporary and the cenozoic East African Vertebrates. Ph. D. diss. Univ. of London.

Huguet, R.; CÁceres, I.; Díez, J. C. y Rosell, J. (1999): Estudio tafonómico y zooarqueológico de los restos óseos de macrovertebrados de la Unidad G.ll de Galería. En Atapuerca. Ocupaciones humanas y paleoecológicas del Yacimiento de Galería. Arqueología de Castilla y León. Carbonell, E.; Rosas González, A.; Díez, J. C. (ed.): 245-264.

KLEIN R. G. (1989): Why does skeletal element abundance differ between smaller and larger bobids at Klassius River Mouth and other archaeological sites? Journal Archaeol. Sciencie 16: 363-381.

KLeIN R. G. y Cruz URibe (1994): The Paleolithic mammalian fauna from the 1910-14 excavations at El Castillo cave (Cantabria). Homenaje a González Echegaray Museo y Centro de Investigaciones de Altamira. Monografías 17: 141-158.

LIEBEFiMAN, D. (1993): Mobility and strain: The strategy of cementogenosis and its aplication to evolution of hunter-gatherer seasonal mobility in the southern Levant during the late Quaternary. Dissertation Harvard University.

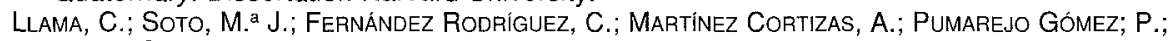
VILLAR Quintero R. y LóPEz Felpeto, M. (1991): Cova de A'Valiña, Castro Verde, Lugo. Un Xacemento do Paleolítico Superior inicial en Galicia. Camp. 1987-1988.

LUPO, K. (2001): Archaeological skeletal report part profiles and diferential transport: ethnoarchaeological example from Hadza bone assemblages. Journal of Anthropological Archaeology 20: 361-378.

LYMAN, R. L. (1994): Vertebrate taphonomy. Cambridge University Press, New York.

MAREAN, C. W. (1998): A Critique of the evidence for scavenging by Neandertals and early modern humans: New data fron Kobech Cave (Zagros mountains, Iran), Die Kalders Cave 1 layer 10 South Africa. Journal of Human Evolution 35: 111-136.

MAREAN, W. C. y Yeun Kin, S. (1998): Musterian large mammals from Kobech Cave. Current antropology 29: 79-113.

MAREAN, C. W. y ASSETA, Z. (1999): Zooarchaeological Evidence for the faunal exploitation behavior of Neandertals and early Modern Humans. Evolutionary Anthropology 8. (1): 22-37.

MARTínez MORENO, J. (1993): Tafonomía y subsistencia; aproximación metodológica para la verificación de la caza en las comunidades cazadoras-recolectoras del Pleistoceno. Bellaterra, Septiembre, 1993. U.A.B. Tesis de licenciatura inédita.

Martínez Moreno, J. (1995): La contrastació de l'activitat predadora en els grups humans arcaics. Cota Cero 11: 25-31.

Martínez Moreno, J. (1997): ¿Existió la caza especializada en el Paleolítico Superior Final en Cataluña? La zona de Serinya, (Cataluña). Revista d'Arqueología del Ponent 7: 35-45. 
Martínez Moreno, J. (1998): El modo de vida Neandertal: Una reflexión en torno a la ambigüedad en la interpretación de la subsistencia durante el Paleolítico Medio Cantábrico. Tesis Doctoral, inédita. U.A.B.

Martínez Valle, R. (1996): Fauna del Pleistoceno Superior en el País Valenciano. Aspectos económicos, huellas de manipulación y valoración paleoambiental. Tesis doctoral inédita. Univ. de Valencia.

MORALES, A. (1990): Arqueología Teórica: Usos y abusos reflejados en la interpretación de las asociaciones de fauna de yacimientos antrópicos. Trabajos de Prehistoria 47: 251-290.

O'CONNELL, J.F.; HAWKES, K. y BLURTON JONES, N. (1990): Reanalysis of large mammal body part transport among the Hazda. Journal of Archaeological Sciencie 17: 301-316.

O'CONNELL, J.F.; HAWKES, K. y BLURTON JONES, N. (1991): Distribution of refuse-producing activities at Hadza residential base camps: Implications for analysis of archaeological site structure. En The interpretations of archaeological spatial patterning. E.M. Kroll; T. D. Price (ed.) Plenium Press. New York: 61-76.

O'CONNELL, J.F.; HAWKES, K. y BLURTON JONES, N. (1992): Patterns in the distribution, site structure and assemblage composition of Hadza Kill-butchering sites. Journal of Archaeological Sciencie, 19: 319-45.

OlaRia C.; GusI, F.; EsteVEZ, J. CASABO J. y RoviRA M. L. (1981): El yacimiento magdaleniense de Cova Matutano. (Villafanes, Castellón). Estudio del sondeo estratigráfico. 1979. Cuadernos de Prehistoria y Arqueología Castellonenses 8: 76-98.

OLARIA C.; GuSI, F. y WATSON J. (1997): El asentamiento magdaleniense de Cova Matutano. (Villafanes, Castellón). En el contexto sociocultural del Würn final del Área mediterránea peninsular. En El Món Mediterraní després del Pleniglacial (18-12000 Bp). J. M Fullola y N. Soler (eds.) Serie monográfica 17 Museu de Arqueología de Catalunya Girona. Col.loqui de Banyolas 1995: 375-382.

Pellicer, M. y Acosta, P. (1995): Nociones previas arqueológicas de la Cueva de Nerja. En Trabajos sobre la Cueva de Nerja. Campaña de 1980-82. Análisis de las cuadrículas NM 80 A-NT 82. 21-45. Morales A.; Martínez Díaz (ed.). Patronato de la Cueva de Nerja, Málaga.

Perales Piquer, C. y Fernández Jalvo, Y. (1990): Estudio tafonómico del yacimiento de Picamoixones. Reunión de Tafonomia y Fosilización: 283-292.

PÉREZ RIPOLL (1977): Los mamíferos del yacimiento Musteriense de Cova Negra. Servicio de Investigación Prehistórica 53, Valencia.

PÉrez RIPOLL (1992): Marcas de Carnívoros, fracturas incipientes y mordeduras de carnívoros en huesos prehistóricos del Mediterráneo español. Instituto de Cultura, Soto de Requeras (Asturias), Excavaciones Arqueológicas de España III: 65-100.

Pumarejo, P.G. y Bernaldo de Quirós (1990): Huellas humanas en huesos, análisis de sus implicaciones económicas. Revista de Arqueología: 108-109.

Pumarejo, P. G. y Cabrera Valdés, V. (1992): Huellas de descarnado sobre restos de fauna del Auriñaciense de la Cueva del Castillo. Espacio, Tiempo y Forma 5 (1): 39-52.

QUESADA LóPEZ, J. M. (1995): Las estrategias de caza durante el Paleolítico Superior Cantábrico. El caso del Oeste asturiano. Complutum 6: 79-103.

Quesada López, J. M. (1997 a). La caza en la prehistoria. Cuadernos de Historia 16: 56.

QUESADA LóPEZ, J. M. (1997 b): Los cazadores recolectores cantábricos del Inter LaugarieLascaux. Complutum 8: 7-32.

QueSADA LóPEZ, J. M. (1997 c): La caza en el Solutrense cantábrico, una nueva perspectiva. Zephyrus 50: 3-36.

RIPOLL LóPEZ, S. (1988): Cueva Ambrosio (Almería) y su posición cronoestratigráfica en el Mediterráneo occidental. BAR International Series 462.

RUEDA, J. M. (1993): L'acció antrópica sobre les matèries dures animals durant el Pleistocé del Nord-est de Catalunya. Tesis Doctoral inédita. Univ. de Girona.

Sото, E. (1984): Restos faunísticos de la cueva del Buxu (Oviedo). Boletín del Instituto de Estudios Asturianos 112: 803-810.

STINER, M. (1994): Honor Amoung Thieves: A Zooarvheological study of Neandertal ecology. Princeton University Press.

Straus, L. G. (1977): Of Deerslayers and Mountain Men: Paleolithic faunal exploitation in cantabrian Spain. En For theory building in archeology. Binford (ed.): 41-78

Straus, L. G. (1983 a): El Solutrense Vasco-Cantábrico, una nueva perspectiva. Centro de Investigaciones y Museo de Altamira 10. 
Straus, L. G. (1992): Iberian before the Iberians, the stone age prehistory of Cantabrian Spain. TORTI J. L. (1983): Avance al estudio cultural antropológico y paleontológico de la cueva del Boquete de Zafarraya. Antropología y Paleoecología Humana 3: 3-12.

VILA Y MITJÀ (1987): L'assentament Paleolitic del Castell (Vilanova de Sau). Cypsela VI: 111123.

VILLAVERDE, V. y Martínez VALLE, R. (1992): Economía y aprovechamiento del medio en el Paleolítico de la región central del Mediterráneo español. En Elefantes, ciervos y ovicápridos. Economia y aprovechamiento del medio en la prehistoria de España y Portugal. Moure Romaníllo (ed.): 77-95.

Villaverde V. y MARTínez Valle, R. (1995): Características culturales y económicas del final del Paleolítico Superior en el Mediterráneo Occidental. Los últimos cazadores del Paleolítico Superior. Villaverde V. (ed.): 79-118.

Villaverde, V.; Martínez Valle, R; Guillen, P. M.; Badal, E.; Zalbidea, L. y García, R. (1997): Els Nivels Magdalenians de la Cova de Les Cendres. Resultats del sondeig del Quadre A17. Aguantis 13-14: 77-115

Yravedra Saínz de los Terreros, J. (2000): Patrones de Representación Anatómica; una hermeneútica equivocada. Arqueoweb. Revista de Internet 3. http://www. ucm. es/info/arqueoweb/ diciembre 2000.

Yravedra Saínz de los Terreros, J. (2001): Zooarqueológica de la Península lbérica. Implicaciones Tafonómicas y Paleoecológicas en el debate de los homínidos del Pleistoceno Superior. Britisch Archaeological Reports International Series 979.

Yravedra Saínz de los Terreros J.; Domínguez Rodrigo, M. y Pérez Ruibal, A. (2002): The out dated basis of anatomical representation patterns for the interpretation of archaeological sites. En Current topics on taphonomy and fossilization. De Rienzi M.; Pardo Alonso, M. V.; Belinchón, M.; Peñalver E.; Montoya, P. \& Márquez-Aliaga, A. (ed.). Valencia: 525-530. 